\title{
Online Learning Satisfaction and Acceptance among Al-Quds University Dental Students
}

\author{
Ra'ed O. Abu Hantash1*, Mohammed Abu Younis², Mohammad Assaf ${ }^{3}$ \\ ${ }^{1}$ Faculty of Dentistry, Al-Quds University, Jerusalem, Palestine \\ ${ }^{2}$ Al-Quds University, Jerusalem, Palestine \\ ${ }^{3}$ Department of Periodontology, Al-Quds University, Jerusalem, Palestine \\ Email: ^rhantash@staff.alquds.edu
}

How to cite this paper: Abu Hantash, R. O., Abu Younis, M., \& Assaf, M. (2020). Online Learning Satisfaction and Acceptance among Al-Quds University Dental Students. Creative Education, 11, 2002-2013. https://doi.org/10.4236/ce.2020.1110146

Received: September 11, 2020

Accepted: October 19, 2020

Published: October 22, 2020

Copyright (C) 2020 by author(s) and Scientific Research Publishing Inc. This work is licensed under the Creative Commons Attribution International License (CC BY 4.0).

http://creativecommons.org/licenses/by/4.0/ (c) (i) Open Access

\begin{abstract}
Objective: Online learning gained credit and acceptance among university students all over the world. COVID-19 outbreak urged educational institutions to adopt that model of learning. A study conducted at Al-Quds university in Jerusalem-Palestine among first, second, third, fourth- and fifth-academic year dental students aimed to evaluate their satisfaction on online learning. Academic year level was also assessed to investigate its effect on E-learning. Materials and Methods: The participants were 328 students (257 females, and 71 males) and their mean age was (20.5 years). A reliable and valid questionnaire was used to assess their perception levels regarding "perceived ease of use" (PEOU), "perceived usefulness" (PU), "perceived online education support service quality" (PSQ), and "online learning acceptance and student satisfaction (OLAS). Data were analyzed using factor analysis, structural equation model techniques, independent sample t-test and logistic regression. Results: Mean scores for the students on the questionnaire domains perceptions of online learning ranged from 2.14 (1.57) to 2.72 (1.70) on a 5-point scale. Cronbach's alpha test is used to measure the reliability and internal consistency of the associated questionnaire domains, (Cronbach's Alpha Based on Standardized Items $>0.896$, and $P$ value $=0.000$ ). Academic year level has significant $(P$ value $=0.000)$ effect on all questionnaire perceptions domains (PEU, PU, PSQ, and OLAS). Conclusions: Online education could be accepted among dental students in the clinical level of dental education (fourth and fifth years). First, second, and third dental year students (preclinical stages) didn't accommodate and adopt E-learning technology. Expenses, COVID19 pandemic, facilities and logistics regarding E-learning could be factors related to what has been yielded in this study. Covid-19 pandamic might affect negatively on the results. Further research should be conducted to explore the value effectiveness of E-learning.
\end{abstract}




\section{Keywords}

Online Learning, Dental Students, Pandemic, Questionnaire Perceptions

\section{Introduction}

Online learning which depends on technical-based tuition and training, provides students with a virtual environments and activities, such as: investigation and audiovisual interaction with a variety of subjects (Al Rahmi et al., 2018). Burden has been placed on institutions of education and higher education to enable access of the virtual courses for online learning (Amado-Salvatierra et al., 2016). E-learning is the teaching that is assisted via information and communications technology, both inside and outside the class room. Although its tools have been used in many settings for a long time, evidence of their application in the education of medical professionals is scarce, especially in the developing countries (Dev et al., 2006; Frehywot et al., 2013). Meanwhile, Yew et al. (2016) suggested that, to study something completely, students needed to hear, discuss, see, query questions about it, and relate concepts to existing experiences. Online learning has been revealed to be effective as other educational methods for gaining of knowledge, skills, and behavior (Means et al., 2009; Cook et al., 2008). Advantages of E-learning include flexibility, course upgrading, adaptive instruction, control over learning activities, and data collection for assessment (Cook \& Triola, 2014). However, regarding the cost effectiveness of E-learning, controversy is existent between saving costs (if compared with face to face education) (Sandars, 2010; Maloney et al., 2015) and high expenses for its development and maintenance (Cook, 2014; Stotzer et al., 2013; Delgaty, 2013).

The spread of corona-virus (COVID-19 pandemic) has led to profound changes in the social interactions among university environment, which forced teaching institutions to adopt emergency E-learning protocols (Murphy, 2020).

However, no study was found to evaluate university students' acceptance to online learning in Palestine during the pandemic of COVID-19, especially among dental students. Therefore, the aim of our study was first to assess dental students' awareness, acceptance and satisfaction towards E-learning at Al-Quds University, and then to evaluate the effect of students' academic level on this educational format.

\section{Materials and Methods}

This study conducted during the spring semester of the academic year 2019-2020 (May-June 2020) at the faculty of Dentistry in Al Quds University-Palestine. A reliable and valid questionnaire (Appendix A) was distributed through a webbased survey among first, second, third, fourth and fifth academic year students. From among a total of eight hundred fifty participants in the survey, the responses of three hundred twenty-eight participants, who were between the ages of 
17 and 24 years, were analyzed (Table 1).

Each student was given a brief explanation of the investigation and the procedures to be undertaken. Informed consent was obtained from each participant.

The questionnaire used in this study was originally developed by Jung-Wan Lee in 2010 who studied possible differences between Korean and American students in terms of their awareness levels regarding online learning support, acceptance, and satisfaction (Lee, 2010). In order to assess the students' attitude toward online learning. Four major domains were rated on a 5-likert scale from "totally disagree $=1$ to totally agree $=5$ ". Those domains were: "perceived ease of use" (PEOU), "perceived usefulness" (PU), "perceived online education support service quality" (PSQ), and "online learning acceptance and student satisfaction (OLAS). PEQU addresses four questions, PU has five questions, PSQ measures three items and OLAS consisted of four questions (Appendix A).

The null hypothesis was that during online learning technology there was no effect of the academic level on students' perception levels regarding online education support service quality, online learning acceptance, and satisfaction.

This study was reviewed and approved by Research Ethics Committee at Al-Quds University; identification number is (133/REC/2020).

\section{Factor Analysis and Reliability Test}

Factor analysis with a varimax rotation procedure was performed using SPSS (Statistical Package for the Social Sciences, version 26.0, Inc., Chicago, IL, USA) in order to clarify the domains of students' attitude towards online learning acceptance and satisfaction. To test factor analysis, Kaiser-Meyer-Olkin (KMO) overall measure of sampling adequacy (MSA) was 0.952 , which is considered marvelous and within the adequate level, and was significant at $p=0.000$. The Bartlett's test of sphericity was 5022.585 (degree of freedom $=120$ ), and significant at $p<0.001$ which indicated a highly significant association among the questionnaire items. In this context, a reliability test was also performed which

Table 1. Demographics of Participants

\begin{tabular}{cccc}
\hline Profiles & Items & No. & Percentage \% \\
\hline Gender & Male & 71 & 21.6 \\
Age (Years Old) & Female & 257 & 78.4 \\
& $17-18$ & 29 & 8.8 \\
Academic Year Level & $19-21$ & 210 & 64.4 \\
& $22-24$ & 88 & 26.8 \\
& First & 61 & 19 \\
& Second & 71 & 22 \\
& Third & 76 & 23 \\
& Fourth & 73 & 22 \\
& Fifth & 47 & 14 \\
\hline
\end{tabular}


showed that the 16-item instrument had Cronbach's alphas over 0.70, ranging from 0.896 to 0.930 (Table 2). This data gives the reliability and the validity of questionnaire used in this study.

\section{Results}

Three hundred twenty-eight dental students were recruited to participate in this study. Two hundred fifty-seven students were females ( $78.4 \%$ of the subjects) and seventy-one were males (21.6\% of the subjects) (Table 1). These students were aware of responding the questionnaire. Students' age ranged from 17 to 24 years with a mean age of 20.51 and standard deviation of 1.42 years (Appendix A).

Regarding students' awareness towards online learning, all the items of the questionnaire (except PEQU and PSQ) showed mean score rating below 2.5 on a 5-pont Likert scale from 1 to 5. PEQU showed 2.51 and PSQ showed 2.72 Table 2. PEQU4 item showed the highest mean score rating (2.91), followed by PSQ 1 that showed a mean score rating of (2.73). On the contrary, OLAS 2 showed the lowest mean score rating of (2.06) Table 2.

Figure 1 shows the distribution of dental students' classes which participated in the study. The distribution of students in the classes were as the following: sixty one students were from first class ( $19 \%$ of the subjects), seventy one were from second class ( $22 \%$ of the subjects), seventy six ( $23 \%$ of the subjects), seventy three were the fourth class ( $22 \%$ of the subjects), and fourth seven were from the fifth class ( $14 \%$ of the subjects) Table 2.

Regarding the impact of academic year level on questionnaire domains ratings, it is obvious that there is an effect of academic year on all domains (Table 3). Using Independent-Samples Kruskal-Wallis Test, there is a significant association between PEQU, PU, PSQ, ALOS items and academic Levels, $(\mathrm{P}$ value $=$ 0.000). It does worth to mention that the mean score ratings of PEQU and PSQ domains were above average for fourth- and fifth-year classes (Figure 2 and Figure 3).

While, the mean score rating for PU domain, fourth- and fifth-year classes were higher than other classes (Figure 4). This study also, showed that mean score ratings of the overall satisfaction and acceptance for the fourth- and fifth-year classes were higher than first, second, and third year classes (Figure 5). Additionally,

Table 2. Reliability of questionnaire.

\begin{tabular}{ccc} 
Variable & No. of items & Cronbach's $\boldsymbol{\alpha}$ \\
\hline Perceived ease of use (PEOU) & 4 & 0.896 \\
Perceived usefulness (PU) & 5 & 0.923 \\
$\begin{array}{c}\text { Perceived online education support service quality (PSQ) } \\
\text { Online learning acceptance and student satisfaction (OLAS) }\end{array}$ & 3 & 0.922 \\
Total reliability of the questionnaire & 16 & 0.930
\end{tabular}


Table 3. Independent-Samples Kruskal-Wallis Test Summery of the effect of the Academic level on Questionnaire items.

\begin{tabular}{cccc}
\hline & Test Statistic & Degree of Freedom & Asymptotic Sig (2-sided test) \\
\hline PEQU & $55.230^{\mathrm{a}}$ & 4 & 0.000 \\
PU & $43.916^{\mathrm{a}}$ & 4 & 0.000 \\
PSQ & $44.564^{\mathrm{a}}$ & 4 & 0.000 \\
OLAS & $45.820^{\mathrm{a}}$ & 4 & 0.000 \\
\hline
\end{tabular}

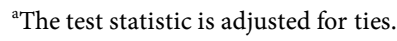

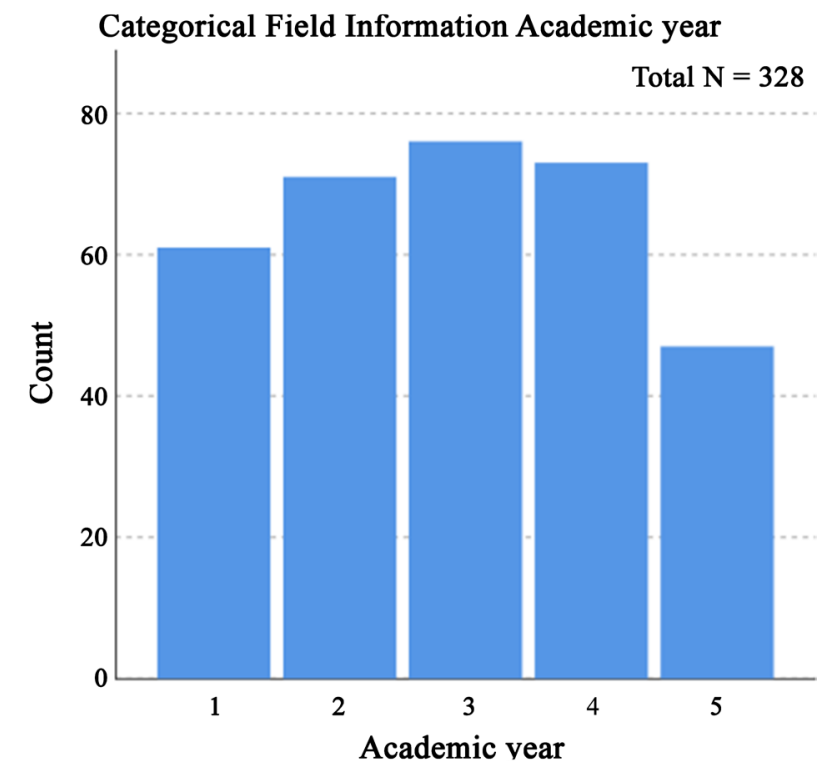

Figure 1. The distribution of the students participated in the study according to the Academic year level. 1: First year, 2: Second year, 3: Third year, 4: fourth year, 5: Fifth year.

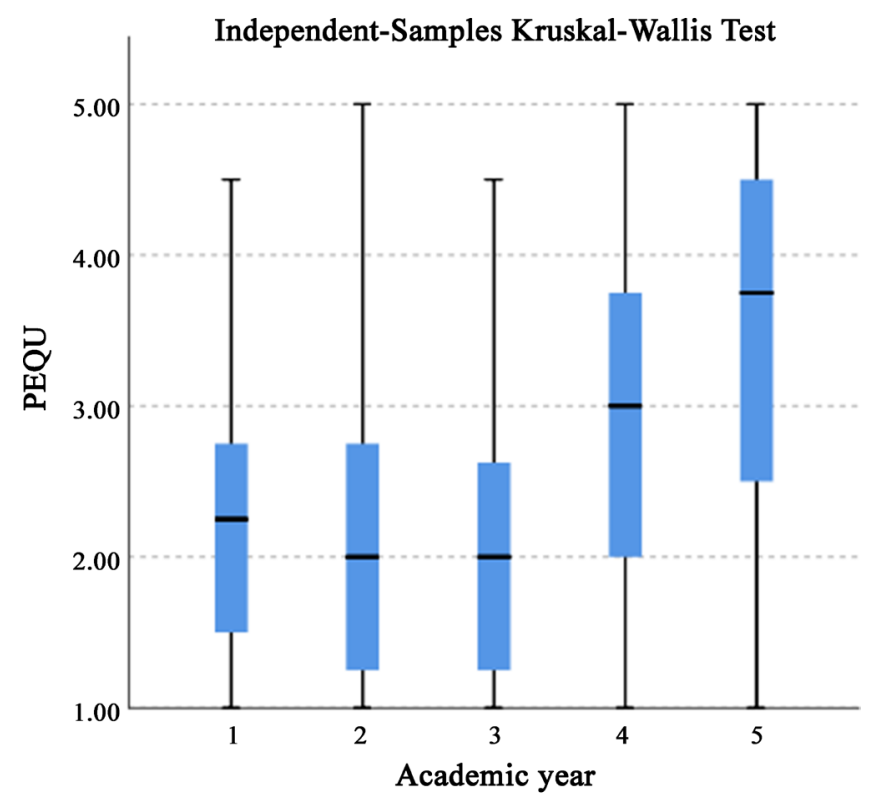

Figure 2. Scoring of Academic Year Level and PEQU item histogram using Independent-Samples Kruskal-Wallis Test. 


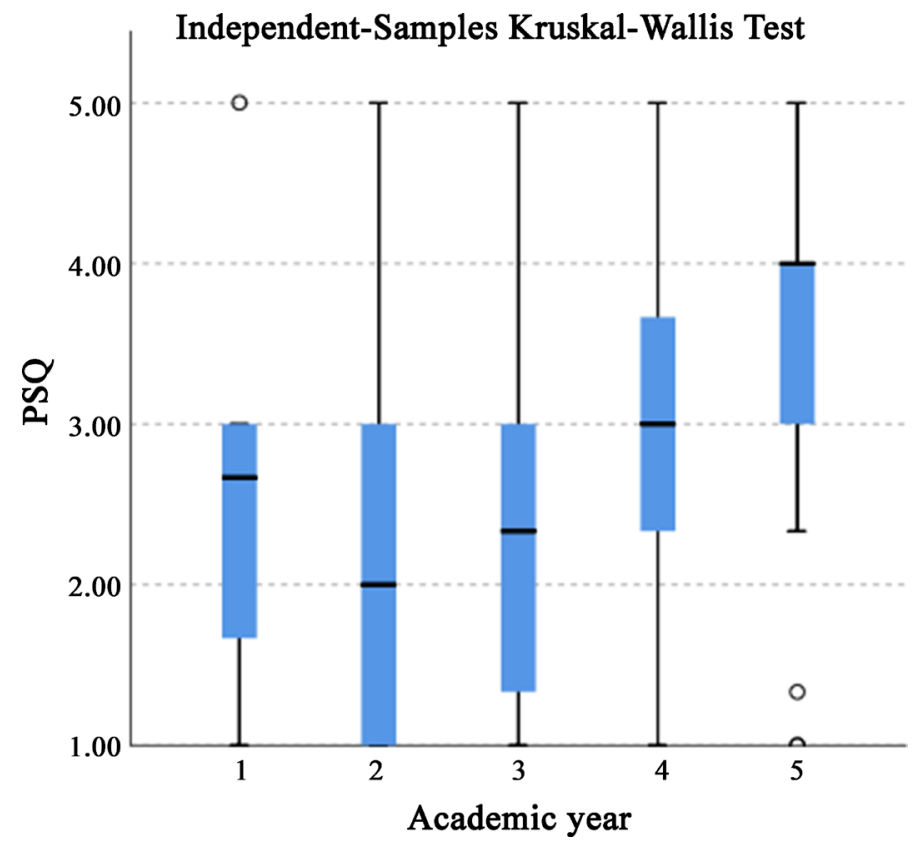

Figure 3. Scoring of Academic Year Level and PSQ item histogram using IndependentSamples Kruskal-Wallis Test.

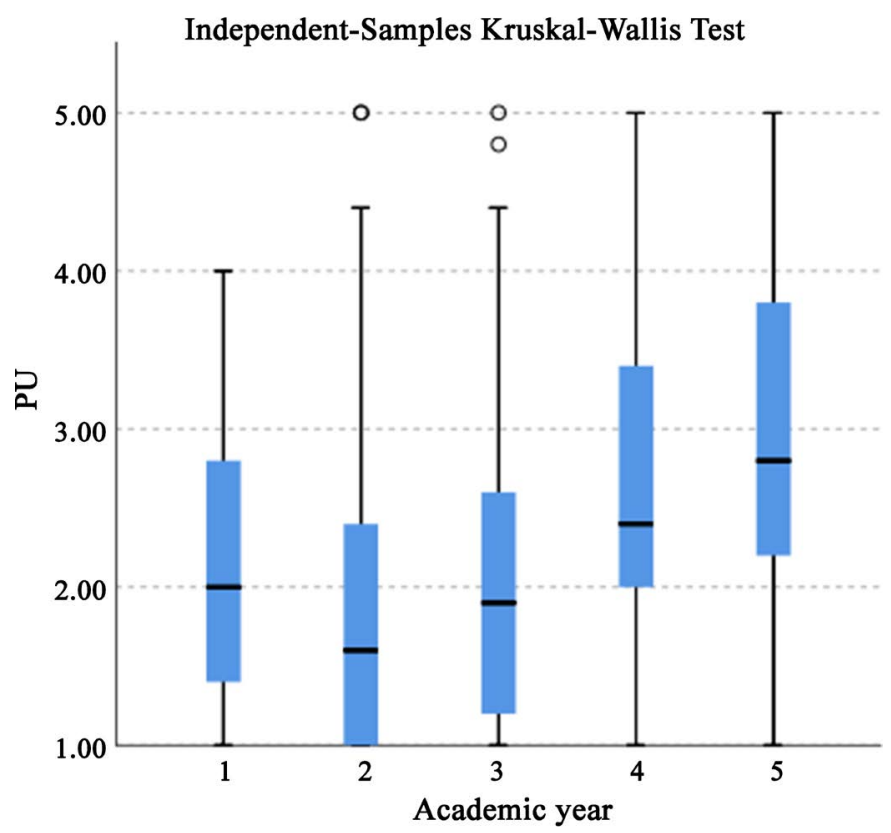

Figure 4. Scoring of Academic Year Level and PU item histogram using IndependentSamples Kruskal-Wallis Test.

fifth year class students scored the highest mean score rating in all questionnaire domains when compared with other classes.

\section{Discussion}

E-learning models have concerned much attention in recent years as possible ways to meet the scarcities as evidenced by face to face learning, and they are 


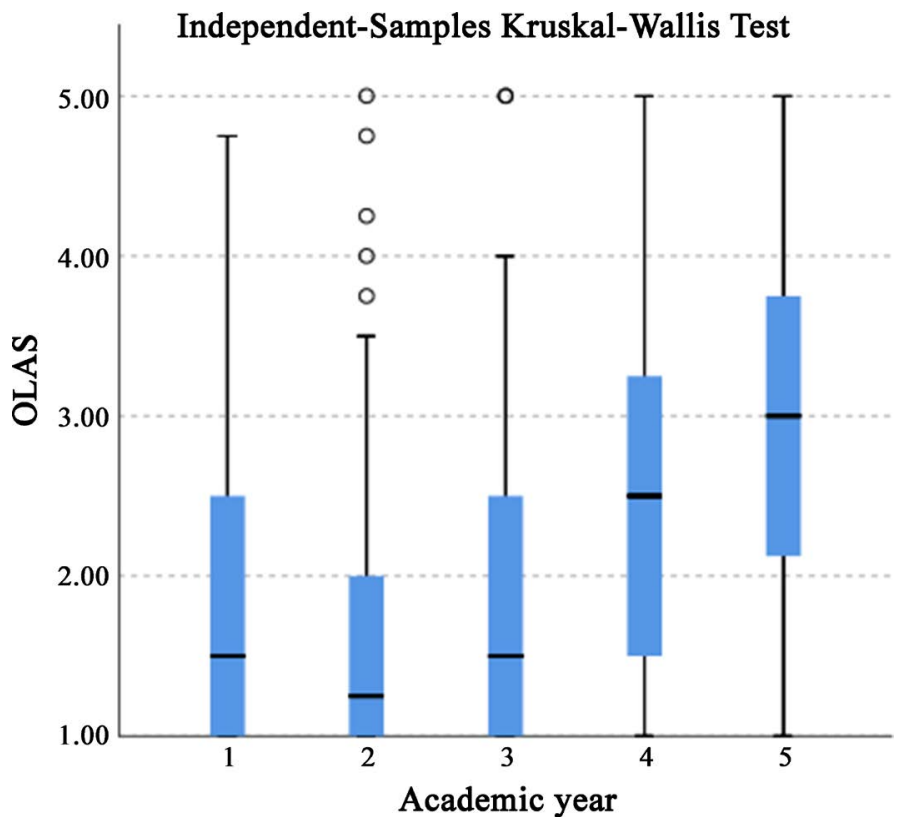

Figure 5. Scoring of Academic Year Level and OLAS item histogram using IndependentSamples Kruskal-Wallis Test.

useful tool for disabling walls to access for health professions' training (Frehywot et al., 2013). However, challenges implemented in e-learning medical education, are: insufficient infrastructure, slow speed and low quality of videos or visual outputs, difficulties in reading content from a computer screen, slow downloading from the internet, inadequate computer services, and frequent electrical power shortages (Agrawal et al., 2011; Kaliyadan et al., 2010; Johnson et al., 2007; Nartker et al., 2010; Erah \& Dairo, 2008; de Maio \& Ferreira, 2001; Corrêa et al., 2003; Obura et al., 2011; Vincent et al., 2003).

A recent coronavirus (2019-nCoV), which caused an epidemic of acute respiratory syndrome in humans in Wuhan, China, started on 12 December 2019 (Zhou et al., 2020). Travel limitations, quarantines, self-isolation, social distancing, and intensified hygiene are considered public governmental measures to manage virus outburst (Cloulthard, 2020). Due to that pandemic, universities were forced to learn and educate students through online learning protocols. E-learning solutions gave the educational institutions the opportunities to overcome the compulsory dismiss of university students. However, online learning is considered a contingency and emergency plan during this pandemic. Educational institutions need well planned strategies, profound budget, adequate technical support, and well-trained staff to adopt this strategy (Kaliyadan et al, 2010; Nartker et al., 2010; Erah \& Dairo, 2008; de Maio \& Feerreira, 2001). In addition, students should have the motivation and the ability that enable them to accept and cope with E-learning. This is critical in tolerating E-learning program regardless of whether such a program is accomplished at the faculty level, or across an educational instituation (Frehywot et al., 2013). According to what was mentioned above, it can be implied that dental students didn't accept online learning 
especially first, second, and third year classes.

The Wang Lee questionnaire (Lee, 2010) which was used in this study to rate students' satisfaction and acceptance towards online learning, was shown to be valid and reliable. As shown in Table 2, this study supports the previous study in terms that the composite reliability (Cronbach's $\alpha$ ) for each domain ranged from 0.896 to 0.930 , suggesting acceptable levels of reliability, indicating the scales had good reliabilities and validities. Meanwhile, Kaiser-Meyer-Olkin (KMO) overall measure of sampling adequacy (MSA) was 0.952 , which is considered marvelous and within the adequate level, and was significant at $p=0.000$. Jung-Wan Lee (2010) investigated the online support service quality, online acceptance, and student satisfaction among Korean and American students. He suggested that the acceptance of online classes would be valuable for both study participants. On the contrary, the participants in this study showed less satisfaction and acceptance towards online learning if compared with previous studies (Al Rahmi et al., 2018; Amado-Salvatierra et al., 2016; Means et al., 2009; Cook et al., 2008; Lee, 2010). All questionnaires' ratings were less than 3 , which can be attributed to the compulsory dismiss of the students and the implementation of the online learning contingency emergency plan due to Covid-19 outbreak. The low acceptance of dental students toward E-learning in this study is consistent with the findings suggested by Noesgaard \& Orngreen (2015), who reported that it was hard to confirm E-learning effectiveness on teaching enhancement as a teacher can apply various approaches as required. Similarly, Yew et al. suggested that students' interactions of hearing, seeing, discussing, asking questions and relating concepts can accomplish a successful learning. In this context, various studies (Corrêa et al., 2003; Kheng, 2008; Akkoyunlu \& Solylu, 2008; Muñoz, 2010) showed that the lack of face to face learning was also a challenge addressed in pure E-learning and contributed to professional loneliness and decreased learning skills. Frequent electrical failure, limitation in bandwidth and inadequate infrastructure could explain the findings of this study. In a study conducted by Frehywot et al. (2013), they found that the potential of E-learning adopts a firm level of institutional keenness in human and infrastructural funds that is not always present in developing countries. However, Palestine has hard social and economic conditions which might be considered one of the aforementioned countries in this regard.

However, the highest mean score which was found in the study, was PEQU4 that measured the ease of online learning and was 2.91. The highest mean score was PSQ that measured students' acceptance towards the faculty and the support service affairs and was 2.72. This reflected the huge efforts presented by the faculty administration and the support service affairs that delivered to the students to facilitate online learning at Al Quds university. Covid-19 pandemic could affect negatively on the findings of this study; however, this study was conducted during this pandemic. Further investigations are required to explore this impact.

Academic level plays a vital role in adopting E-learning. The findings of this 
study, showed that higher dental students' classes (fourth and fifth years) were more satisfied and accepted online education when compared with other classes. This finding was consistent with the study conducted by Wittich et al. (2017) who conducted a study and investigated e-learning in graduate medical programs, and they reported that in US most internal medicine residency programs use e-learning and they have more positive perceptions of E-learning. Although more programs were used as (live, real-time, and simultaneous) utilization learning methods than virtual where learners are responsible for self-teaching and instruction. Accordingly, higher academic level classes can accept and are mature enough to adopt e-learning, due to the fact that they were taught through the first three years via conventional learning methods (face to face), and online learning added a new era to their learning experiences. On the contrary, first, second and third years were still in scarce to conventional teaching methods, in terms of discussing, hearing and asking questions to the instructors. However, this needs further investigation to consider that in online learning.

\section{Conclusion}

In the light of the current study, the following can be concluded and recommended.

Dental students' acceptance and satisfaction towards online education were below average during COVID-19 outbreak. Further investigation is required to explore the impact of COVID-19 outbreak on students' attitudes towards online learning.

Faculty support and online education support service affairs had an effect in raising students' awareness and acceptance towards online learning.

Online learning acceptance and student satisfaction questionnaire is a valid and reliable tool that can be used in further researches. This study recommends it for measuring satisfaction and acceptance online learning among university students.

Academic year level could be attributed to have an impact on students' online learning acceptance. Fourth and fifth year dental students accepted and were more satisfied with online learning when compared with other year classes. Further investigation is needed to investigate this finding.

It is also recommended to educate teachers on methods to make E-learning more convenient and efficient for students.

Further efforts and well-planned strategies are needed to dissolve the existent challenges to promote and enhance the sustainability of online learning especially among dental students.

\section{Conflicts of Interest}

The authors declare no conflicts of interest regarding the publication of this paper.

\section{References}

Akkoyunlu, B., \& Soylu, M. (2008). A Study of Student's Perceptions in a Blended Learning Environment Based on Different Learning Styles. Journal of Educational Technol- 
ogy \& Society, 11, 183-193.

Agrawal, S., Kumar, M. A., Shrivastava, K. S., \& Pant, M. S. (2011). Training the Trainees in Radiation Oncology with Telemedicine as a Tool in a Developing Country: A TwoYear Audit. International Journal of Telemedicine and Applications, 2011, Article ID: 230670. https://doi.org/10.1155/2011/230670

Al Rahmi, W. M., Alias, N., Othman, M. S., Alzahrani, A. I., Alfarraj, O., Saged, A. A. et al. (2018). Use of E-Learning by University Students in Malaysian Higher Educational Institutions. A Case in Universiti Teknologi Malaysia. IEEE Access, 6, 14268-14276. https://doi.org/10.1109/ACCESS.2018.2802325

Amado-Salvatierra, H. R., Hilera, J. R., Tortosa, S. O., Rizzardini, R. H., \& Piedra, N. (2016). Towards a Semantic Definition of a Framework to Implement Accessible e-Learning Projects. Journal of Universal Computer Science, 22, 921-942.

Cloulthard, P. (2020). Dentistry and Coronavirus (COVID-19) Moral-Decision Making. British Dental Journal, 228, 503-505. https://doi.org/10.1038/s41415-020-1482-1

Cook, D. A., \& Triola, M. M. (2014). What Is the Role of e-Learning? Looking Past the Hype. Medical Education, 48, 930-937. https://doi.org/10.1111/medu.12484

Cook, D. A. (2014). The Value of Online Learning and MRI: Finding a Niche for Expensive Technologies. Medical Teacher, 36, 965-972. https://doi.org/10.3109/0142159X.2014.917284

Cook, D. A., Levinson, A. J., Garside, S., Dupras, D. M., Erwin, P. J., \& Montori, V. M. (2008). Internet-Based Learning in the Health Professions: A Meta-Analysis. JAMA, 300, 1181-1196. https://doi.org/10.1001/jama.300.10.1181

Corrêa, L., de Campos, A. C., Souza, S. C., \& Novelli, M. D. (2003). Teaching Oral Surgery to Undergraduate Students: A Pilot Study Using a Web-Based Practical Course. European Journal of Dental Education, 7, 111. https://doi.org/10.1034/j.1600-0579.2003.00291.x

Delgaty, L. (2013). A Critical Examination of the Time and Workload Involved in the Design and Delivery of an e-Module in Postgraduate Clinical Education. Medical Teacher, 35, e1173-e1180. https://doi.org/10.3109/0142159X.2012.737963

Dev, P., Hoffer, E. P., \& Barnett, G. O. (2006). Computers in Medical Education. In E. Shortliffe, \& J. J. Cimino (Eds.), Biomedical Informatics (pp. 737-762). New York: Springer Science and Business Media, LLC. https://doi.org/10.1007/0-387-36278-9_21

Erah, P. O., \& Dairo, E. A. (2008). Pharmacy Students' Perception of the Application of Learning Management System in Patient-Oriented Pharmacy Education: University of Benin Experience. International Journal of Health Research, 1, 63-72. https://doi.org/10.4314/ijhr.v1i2.47917

Frehywot, S., Vovides, Y., Talib, Z., Mikhail, N., Ross, H., Wohltjen, H. et al. (2013). E-Learning in Medical Education in Resource Constrained Low- and Middle-Income Countries. Human Resources for Health, 11, 4. https://doi.org/10.1186/1478-4491-11-4

Johnson, P., Ghebreyohanes, G., Cunningham, V., Kutenplon, D., \& Bouey, O. (2007). Distance Education to Prepare Nursing Faculty in Eritrea: Diffusion of an Innovative Model of Midwifery Education. Journal of Midwifery \& Women's Health, 52, e37-e41. https://doi.org/10.1016/j.jmwh.2007.07.002

Lee, J.-W. (2010). Online Support Service Quality, Online Learning Acceptance, and Student Satisfaction. Internet and Higher Education, 13, 277-283. https://doi.org/10.1016/j.iheduc.2010.08.002

Kaliyadan, F. F., Manoj, J. J., Dharmaratnam, A. D., \& Sreekanth, G. G. (2010). SelfLearning Digital Modules in Dermatology: A Pilot Study. Journal of the European Academy of Dermatology and Venereology, 24, 655-660. 
https://doi.org/10.1111/j.1468-3083.2009.03478.x

Kheng, S. (2008). The Challenges of Upgrading from ISPO Category II Level to Bachelor Degree Level by Distance Education. Prosthetics and Orthotics International, 32, 299-312. https://doi.org/10.1080/03093640802109764

de Maio, M., \& Ferreira, M. C. (2001). Experience with the First Internet-Based Course at the Faculty of Medicine, University of São Paulo. Revista do Hospital das Clinicás, 56, 69-74. https://doi.org/10.1590/S0041-87812001000300002

Maloney, S., Nicklen, P., Rivers, G., Foo, J., Ooi, Y. Y., Reeves, S. et al. (2015). A Cost Effectiveness Analysis of Blended versus Face-to-Face Delivery of Evidence-Based Medicine to Medical Students. Journal of Medical Internet Research, 17, e182.

https://doi.org/10.2196/jmir.4346

Means, B., Toyama, Y., Murphy, R., Bakia, M., \& Jones, K. (2009). Evaluation of Evidence Based Practices in Online Learning: A Meta-Analysis and Review of Online Learning Studies. Washington DC: US Department of Education.

Murphy, M. P. A. (2020). COVID-19 and Emergency e-Learning: Consequences of Securitization of Higher Education for Post-Pandemic Pedagogy. Contemporary Security Policy, 41, 492-505. https://doi.org/10.1080/13523260.2020.1761749

Muñoz, D. C. (2010). Effective e-Learning for Health Professional and Medical Students: The Experience with SIAS-Intelligent Tutoring System. Studies in Health Technology and Informatics, 156, 89-102.

Nartker, A. J., Stevens, L., Shumays, A., Kalowela, M., Kisimbo, D., \& Potter, K. (2010). Increasing Health Worker Capacity through Distance Learning: A Comprehensive Review of Programmes in Tanzania. Human Resources for Health, 8, 30.

https://doi.org/10.1186/1478-4491-8-30

Noesgaard, S. S., \& Orngreen, R. (2015). The Effectiveness of e-Learning: An Explorative and Integrative Review of the Definitions, Methodologies and Factors That Promote e-Learning Effectiveness. The Electronic Journal of e-Learning, 13, 278-290.

Obura, T., Brant, W. E., Miller, F., \& Parboosingh, I. J. (2011). Participating in a Community of Learners Enhances Resident Perceptions of Learning in an e-Mentoring Program: Proof of Concept. BMC Medical Education, 11, 3. https://doi.org/10.1186/1472-6920-11-3

Zhou, P., Yang, X.-L., Wang, X.-G., Hu, B., Zhang, L., Zhang, W. et al. (2020). A Pneumonia Outbreak Associated with a New Coronavirus of Probable Bat Origin. Nature.

Sandars, J. (2010). Cost-Effective e-Learning in Medical Education. In K. Walsh (Ed.), Cost Effectiveness in Medical Education (pp. 40-46). Oxon: Radcliffe.

Stotzer, R. L., Fujikawa, K., Sur, J., \& Arnsberger, P. (2013). Cost Analysis of a Distance Education MSW Program. Journal of Teaching in Social Work, 33, 357-368. https://doi.org/10.1080/08841233.2013.826318

Vincent, D. S., Berg, B. W., Hudson, D. A., \& Chitpatima, S. T. (2003). International Medical Education between Hawaii and Thailand over Internet2. Journal of Telemedicine and Telecare, 9, S71-S72. https://doi.org/10.1258/135763303322596336

Wittich, C. M., Agrawal, A., Cook, D. A., Halvorsen, A. J., Mandrekar, J. N., Chaudhry, A. et al. (2017). E-Learning in Graduate Medical Education: Survey of Residency Program Directors. BMC Medical Education, 17, 114.

https://doi.org/10.1186/s12909-017-0953-9

Yew, T. M., Dawood, F. K., Narayansany, K. S. et al. (2016). Stimulating Deep Learning Using Active Learning Techniques. Malaysian Online Journal of Educational Sciences, 4, 49-57. 


\section{Appendix A. Summary of Descriptive Statistics and the Questionnaire Items}

\begin{tabular}{ll}
\hline Questionnaire Item (5-Point scale ranging from "totally disagree $=1$ " to "totally agree $=5 ")$ & Mean (SD) \\
\hline PEQU & $2.51(1.75)$
\end{tabular}

1. I find it easy to use online learning system to do what I want it to do

$2.54(1.32)$

2. I find the online learning system is clear and understandable for me

2.27 (1.26)

3. It is easy for me to become skillful at using the online learning system

2.33 (1.34)

4. I find the online learning system easy to use

$2.91(1.37)$

PU: Using online learning system

1. enables me to accomplish programs more quickly

2. improves my ability to accomplish academic tasks

3. increases my productivity in accomplishing academic tasks

4. enhances my effectiveness in accomplishing academic tasks

5. I find online learning system useful in my study completion.

PSQ: When I register for online courses, I expect

1. To have adequate feedback and support services from faculty

2. To have adequate information and support services from institutions

3. To have adequate support services from student service coordinators

Online learning acceptance and satisfaction (OLAS)

1. If I need to study for advanced degrees (programs), I would expect to use the online learning system.

2. If asked, I would likely recommend the online learning system as an ideal learning platform.

3. For future advanced degrees (programs/certificates), I would probably use the online learning system. 